\title{
Assessing Social Capital Accumulation in Service System Development with Service- Dominant Logic View
}

\author{
Hung-wei Chen Fu-ren Lin \\ Institute of Service Science, National Tsing Hua University, \\ 101, Sec. 2, Kuang-Fu Road, Hsinchu 30013, Taiwan \\ hungwei.chen@iss.nthu.edu.tw frlin@iss.nthu.edu.tw
}

\begin{abstract}
Under the global trend of urbanization, a city ecosystem could be viewed as an integration of various service systems with the Service-Dominant Logic (S-DL) view. To study the composition of the service systems, social capital accumulation could be used to assess the resource distribution in the system development under the value-oriented perspectives of $S$-DL. Prior researches on related topics usually focused on the performance of social capital. This paper aims to assess social capital by studying the resource integration process, and to answer how social capital was accumulated along with the service system development. Grounded on the S-DL, this research studies the service system development of a traditional market revitalization project by actornetwork analysis using the field data from a 30-month ethnographical work. A conceptual framework integrating social capital theory and $S$-DL perspective was developed. We demonstrate the process of evaluating the social capital generation and integration during value creation, which approaches its accumulation process. We anticipate the framework of accessing the social capital accumulation can reveal the structural holes of service systems by analyzing the accumulated conditions, facilitating the involved actors' decision making, and communicating the value propositions with the public.
\end{abstract}

\section{Introduction}

The service economy for a city composes various industries to form the ecosystems to sustain human societies [1][2]. A city ecosystem could be viewed as an integration of various service systems through the lens of Service-Dominant Logic (S-DL), which sustains city life in environmental, economic, and social dimensions [3][5]. Under the S-DL view, "service is the fundamental basis of exchange" which indicates a way to analyze system development [6]. Value becomes a common term used to describe the assessment of outcomes since tangible goods are treated as a distribution mechanism for service provision [7]. Value co-creation and co-destruction are main processes that stakeholders exchange resource among each other to maintain a service system [8][11]. In a value creation system, the major resource is called operant resource, including actors' knowledge and skills which are intangible and dynamic [7].

To study the composition of a service system, social capital could be used to describe the resource distribution for assessing the development of a social organization or network [12]. It's an intangible but valuable asset that is generated during social interaction, which could also be exchanged in the structure of certain social relationship [13]. In the perspective of resource integration, service system development is a process that stakeholders generate and exchange social capital. Resources delivered in such patterns as structural, relational, and cognitive dimensions are accumulated as stakeholders participating in the service system continue interacting [14].

However, the mechanisms of how social capital is accumulated haven't been seen in literatures. Scholars in the past decades had tried hard to define the attributes of social capital [15],[16] and how its role affected the stakeholders in specific social relationships [17],[18]. Some researches proposed models to describe how social capital was accumulated, but still lack solid field evidence support [19],[20]. These studies on social capital accumulation are used to face the challenges of time correlation; that is, researches able to get enough information about the accumulated social capital and its affection on the system tend to be conducted in a long period of time for data collection.

This research aims to assess how social capital was accumulated along with the development of service system. By taking the lens of S-DL, value generated by social capital exchanging could be evaluated under the value-oriented view. We conducted the research with 30-month ethnographic field work to study a traditional market revitalization 
and the social capital accumulation process of the renovated service system. With the systematic perspective of Actor Network Theory (ANT), the composition and evolution of service system could be identified for analyzing the distribution of social capital [21][22].

This research will contribute to understanding the social capital accumulation for service system development with field evidences based on S-DL and ANT. These findings may shed the light on service system innovation and sustainable urban development.

\section{Theoretical Foundation}

This research takes the lens of S-DL, using the value-oriented view to analyze how stakeholders accumulate social capital along with the service system development. Social capital is utilized as the underlying theory to discuss the attributes of resource exchange and integration [12],[13]. Scholars in various disciplines took advantage of social capital to explain the integration of the structure of social relations. Both tangible profit and cognition-oriented measurement were used to assess the value creation process in social capital researches; however, the majority of usage was to assess personal feeling about a specific event or service (e.g., satisfaction) and common understanding about specific systems (e.g., communities, networks, or IT systems) [12],[23][26], which fit the perspectives of S-DL while evaluating service systems. As our former discussion, social capital could be used to describe the resource distribution for studying the composition of service systems. An integrated view is required to assess the social capital accumulation in order to clarify the underlying mechanisms of system development.

A prior research [14], extending from Tsai and Ghoshal's framework of social capital dimensions [12], discussed the value creation by assessing the relationship existing within social capital for social enterprises. The framework only identified the attributes of the social relation structure of a social enterprise and its involved stakeholders, but how social capital was accumulated and how it affected the value co-creation of an entire service system are still unclear. Reviewed researches related to the topics of social capital accumulation and value co-creation usually end up with defining capital attributes or analyzing the interaction of a target network [8],[15][18],[27]. It's still hard to find any researches assessing the process of social capital accumulation corresponding to value creation with involved stakeholder.

\subsection{Social capital accumulation}

The term social capital was originally used to describe the relational resources that are used to assess the development of a social organization or network [12]. It was described as current or potential resources related to a long-term recognized network of relations that enable people to work together for common purposes in groups and organizations [28],[29]. Thus, the concept of social capital has been explored in multidisciplinary researches for discussing the social institution development (e.g., networks, norms, and social trust), especially the coordination and cooperation on the investment in social relations with expected returns [30][31]. Embedded with a social structure, social capital is differentiated from other types of resource among market, social, and hierarchical relations [32]. According to the first conceptual theoretical model of social capital within an organizational setting [33], social capital possesses many attributes describing the relationships within social networks. Then, the concept was developed into three dimensions [12][14][34][35]: structural capital (tangible connections among stakeholders), relational capital (personal relationships developed through interactions), and cognitive capital (common perspectives and understandings of collective goals on the system level). Our previous work had already emphasized social capital in an organizational setting, using three case studies on social enterprises to explain how individuals within a service system were represented as a group of people or stakeholders [14]. These dimensions were also well adopted to study the performance of an organization [36][38], and could be able to analyze the stakeholders' behaviors for accessing the mechanism of social capital accumulation within a service system (

Table 1).

Social capital accumulation was found with a close connection of social participants [19]. This process involves multiple stakeholders during establishing and maintaining social ties, which might be unequal to individuals [16]. As the outcome, several reviewed literatures show the advantages gained by a specific group of people through the view of accumulating social capital [17],[18]. We take it as the process that moves the service system forward by reallocating the resource. However, most of the reviewed literatures did not provide enough insight to clarify the mechanism of accumulation. The majority of found outcomes are field-limited indicators, definitions, affections, and observation dimensions [15][18]. Several models were found related to social capital accumulation; however, their main focus was on the performance rather than the mechanism 
[19],[20]. According to our review, social capital accumulation is worth to study for knowing the mechanism underlying system development. A valueoriented perspective is required to analyze these intangible contents which deeply lying on the interaction within the system.

Table 1. Three highlighted dimensions of social capital and the implications to stakeholders' behavior within a service system.

\begin{tabular}{|c|c|c|}
\hline \multicolumn{2}{|c|}{ Social capital dimension } & \multirow[t]{2}{*}{ Implications to stakeholders' behavior within a service system. } \\
\hline Type & Focus & \\
\hline Structural & $\begin{array}{l}\text { Extent of } \\
\text { connection } \\
\text { between actors. }\end{array}$ & $\begin{array}{l}\text { 1. The potentials or possibilities for stakeholders' capacity to access information, } \\
\text { resources, and support [35]. } \\
\text { 2. Strong social interactions and ties are beneficial and productive resources for } \\
\text { organizations. High connection permits stakeholders in the same service } \\
\text { system to know each other, to share important information, and to create } \\
\text { common view [12]. }\end{array}$ \\
\hline Relational & $\begin{array}{l}\text { Quality of } \\
\text { actors' } \\
\text { connection and } \\
\text { relationship. }\end{array}$ & $\begin{array}{l}\text { 1. Personal relationship and connection people have developed through a series } \\
\text { of interactions within the network [39]. } \\
\text { 2. Connection and relationship with a high quality provide stakeholders resources } \\
\text { to maintain the networks, such as establishing respect, trust, trustfulness, and } \\
\text { friendliness with other stakeholders. }\end{array}$ \\
\hline Cognitive & $\begin{array}{l}\text { Shared view } \\
\text { and interest } \\
\text { between actors. }\end{array}$ & $\begin{array}{l}\text { 1. The shared representations, interpretations and systems of meaning among } \\
\text { stakeholders, and facilitating common perspectives and understandings of } \\
\text { collective goals [38]Error! Reference source not found.. } \\
\text { 2. Cognition in networks of service system help construct shared norms, goals, } \\
\text { and languages between stakeholders, and promote the translation. }\end{array}$ \\
\hline
\end{tabular}

\subsection{Service-Dominant Logic}

Service-Dominant Logic (S-DL) emphasizes value creation using the service system view. Concepts of operand and operant resources were used to explain how marketing theories and practices were evolving [6]. Operand resources are tangible and static, which generate value under additional actions (e.g., material and equipment generate value while people use it). Operant resources are intangible and dynamic, which are able to transform operand resources or generate value (e.g., experts use material and equipment to be productive). The view of resources could explain how stakeholders interact and their transaction within and among service systems [7]. Thus, a service system could be described as an integration of people, technology, internal and external organizations that co-create value aiming to improve the quality of system [40].

With the S-DL perspective, the value creation process through collaboration in a network could be generalized to discuss a service system development. The latest publication of the original S-DL authors, Lusch and Vargo, indicates that value co-creation is coordinated through actor-generated institutions and institutional arrangements [6], which means that the sustainability of value co-creation relies on the stabilization of actor-formed networks. The institution generating processes including both value co-creation and co-destruction are affected by different powers involved [8],[11]. Stakeholders exchange resource among each other and accumulating the social capital on the level of the entire service system.

Taking the advantages of S-DL, scholars adopted the unique perspective to analyze resource integration within organizations [8],[41]. It was also used in a large scale of complex service systems [27] and to define the roles of actors [42]. In this research, S-DL provides a value-oriented view to describe the patterns of how social capital is generated, exchanged, and then accumulated.

\subsection{Actor Network Theory}

While taking a service system as the subject, networks which compose the system would be the units for analyzing. A well-known theory, Actor Network Theory (ANT), provides a methodology to identify the relationships and interactions within and among networks [43]. It treats human (actor) and nonhuman (actant) equally to trace their roles, then describing how an actor-network was formed by a series of actions taken from pursuing self-interests to reaching common goals [21]. An important feature that connects involved stakeholders to negotiate their common foci, known as obligatory passage point 
(OPP), is seen as a value deliverer of the integrated network.

ANT was used to demonstrate the network analysis results. It provides a way to collect crosssectional snapshots from a continuous system development [44],[45]. Our previous work adopted a method of system analysis based on the perspectives of ANT (Figure 1), which describes how actors (B-E) achieve their own goals by overcoming obstacles through the focal actor (A) which serves as an OPP [22]. We follow this method to describe the contents from the field for approaching the social capital accumulation in this research.

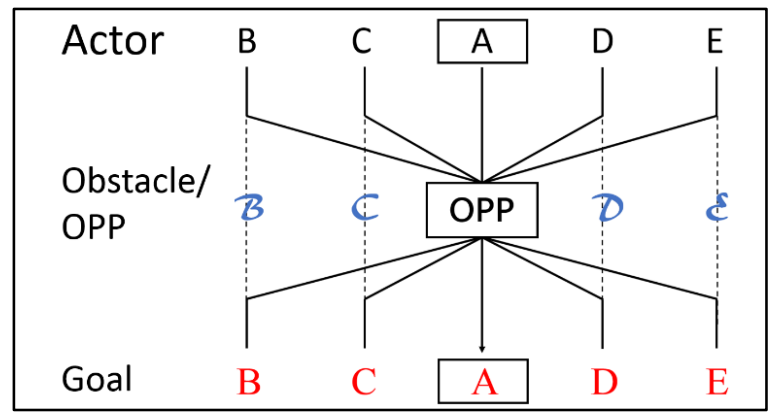

Figure 1. System analysis base on ANT.

\section{Case study}

The main focus of this research is to assess the social capital accumulation of a service system development via the S-DL view. In order to understand the intangible process of generating social capital, a qualitative approach is considered appropriate for this research. For collecting enough data to understand a service system development, a 30month ethnographic field work was conducted to study a traditional market revitalization project [46], the Dongmen Market (DMM), discovering the insight of how the value of its service system was renovated from a declined market to an expected youth hub.

Ethnography is a methodology that is generally applied to study phenomena in relation to their context, by which researchers act objectively as the probes to sense data from the field. In this research, multiple identities such as a complete observer, observer-asparticipant, and participant-as-observer [48], were used while engaging targeted subjects to maximize the collected insight. The co-author was one of the facilitators in DMM revitalization, who was able to reach most of the occasions in the field. Data with first- and second-hand collections, known as the thick description [47], are integrated by field notes, meeting minutes, social media, and interview reports. In the data collecting period, around 100 stakeholders were involved, from which we inquired data to understand the development of service systems. This section presents the outcomes of service system analysis. For the consideration to the conflict of interest in the field, sensitive information is partially disguised.

\subsection{Introduction to Dongmen Market revitalization}

Under the global trend of urbanization, traditional indoor and outdoor markets were challenged by the modern retailing systems and the pressures of urban renewal [49][50]. Dongmen Market (DMM), the biggest market of Taiwan in 1900s, had faced the similar dilemma between urban renewal and traditional culture preservation since it is located in Hshichu City, where the world largest semiconductor manufacturing ecosystem is located in Hsinchu Science Park starting from 1980s. The business of DMM had declined along with the industry shifting to high-tech, and has been replaced by supermarkets, outlets, and modern department stores. Store rooms in DMM building were idled because the store runners couldn't survive with their original business models. Over $60 \%$ of vacancy rate of the floor area (over 9,000 square meters) was reported in the beginning of this research.

To revitalize the declined market, the CrossBorder Governance and Civic Culture Innovation Project (CBGP) was kicked off in 2015 to renovate the market by cooperating universities, city government, store runners, and other related stakeholders. An organization KhuiMng Studio (KMS) was founded as the focal actor to facilitate the revitalization. By a series of design and innovation, the service system of DMM was going to become a youth hub, which provides a relatively lower price for startups to rent a store space that would create new imagination from the traditional retailing service system. Near 30 new stores with youth entrepreneurs opened in DMM since the CGBP was kicked off. The service system of DMM was renovated from a declined market to a youth market. To study the social capital, we studied these two service systems of DMM in a period of 30 months. Then, the accumulation process could be assessed by analyzing the roles of actors and their value creation.

\subsection{The service system analysis of the declined market}

At the beginning of this research, DMM was a typical declined market with a high vacancy rate. Most of original store owners ranging from 60 to 90 years old, stayed in their store space because of customary rather than earning money. Although few groceries 
selling fresh foods in the morning, only elder consumers would come. Because of the non-prosperity in DMM, the city government decided to turn off half of the lights in afternoons to save energy. Thus, the appearance of closed stores and dark surroundings created a scary image to the public.

To sustain the urban living systems, the contemporary DMM revitalization started with the collaboration between the local university and the government via CBGP. The city government was open to seek solutions to create new market services in DMM rather than only preserved the old market business; therefore, the CBGP team proposed to create a youth hub in the idled zone of DMM. An organization, KhuiMng Studio (KMS), was founded by students from local universities, rented two idled store rooms for holding events (e.g., workshops, lectures) with the support of the CBGP. Some faculties from local universities then started to arrange learning activities and research projects in DMM. Young generations had engaged with DMM through events or school works, which slowly changed their stereotype of DMM. Some youth startups then came to DMM for searching opportunities to start business due to the experimental events held by the KMS. They found potentials besides the original service system. Facing the instant changes compared with the past decades, store owners were xenophobic to the newcomers. Some of their suspicion had changed to the expectation in pace with more youths joining DMM.

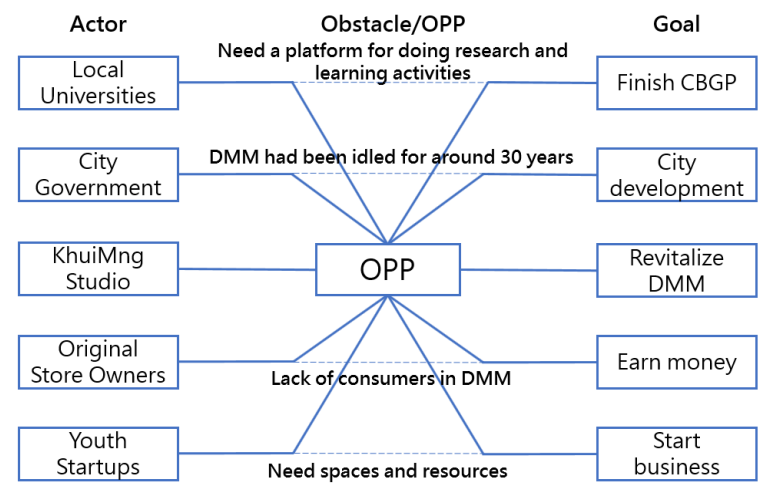

Figure 2. Actor-network analysis to the service system of declined market.

The goals of identified actors in the service system were totally different (Figure 2). The created OPP was an intangible value that the young generation joins DMM. To pursue self-interest under this common view, actors had taken different actions among each other. The service system of declined market was gradually changed along with the revitalization, as the outcome of social capital accumulation.

\subsection{The service system analysis of youth market}

With the effort of identified actors, the first official outcome of DMM revitalization was reported on Oct. $26^{\text {th }}$ in 2016 . The city government announced the future roadmap of the Dongmen Youth Hub (DMYH) with the collaboration of local universities and youth startups. Half year later, new coming entrepreneurs flocked to search for store space in DMM by virtue of stabilized business environment established by prior youth startups. According to the field data, the survival of prior youth startups was one of the major reasons that convinced the incoming youth entrepreneurs. Along with the second batch of entrepreneurs in March, 2017, and the opening of DMYH, over 20 new youth startups had joined DMM service system in the second half of 2017.

DMM soon became a famous place of nightlife in the old city with several stylish caterings opened by entrepreneurs. Because of the lack of space and resource in the old market, startups decided to share tables and chairs for their consumers and not to offer the same items of goods for preventing vicious competition. Several original store owners then increased their business hours to the evening for catching new consumers. With the demand of understanding DMM revitalization, the KMS then offered guided tours and created documentary for promotion. Local universities then held a large forum with the topic of entrepreneurship, for both moving the CBGP forward and demonstrating the revitalization outcome. The developed unique service system attracted consumers from both inside and outside the city, people were fond of the integration between old and new stores that was known as the emerging DMM culture.

In pace with the rapid development of the DMM, the policy for the DMYH made by the city government focused on attracting youth startups to create cultural and creative industries. A series of news reports and official advertisements were created to promote the governmental effort on DMM revitalization. However, there existed a gap between the created pretty images and the revitalization of the old market. Many people felt disappointment when they paid a visit because they saw most of stores were still unrevitalized. This situation happened seriously in the zone of DMYH. The youths were exhausted with the problem of the old building (e.g., high temperature, leaking, and odor) but could not find an effective way to ask the city government to speed up the renewal of the public area. In addition to the aforementioned issues, the forthputting of public resources also caused conflicts. 
The most indicative issue was the usage rights of the co-working space in the DMYH. Because of the considerations of safety and administration, the city government postponed the opening of the space to youths but still lent it to official organizations, which irritated the youths. Almost all startups in DMYH argued on the usage right issue, including the members of the KMS because they felt they were not respected.

The ongoing issues in DMM drive the development of its service system, including actors with different goals (Figure 3). Through the interactions among actors, including collaboration and conflict, an OPP was formed that delivered the value which was convincible for the public to understand this revitalizing youth market. The field data present evidences that social capital was accumulated to facilitate OPP creation, which will be analyzed in the next section.

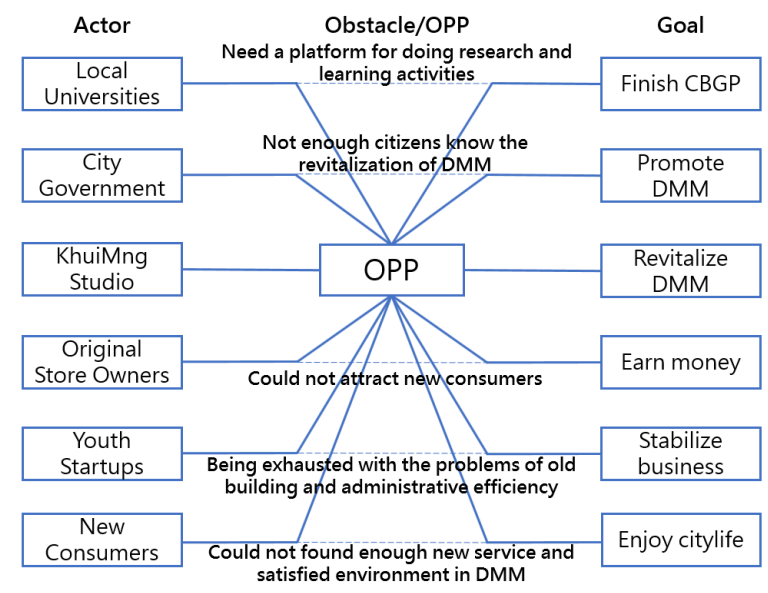

Figure 3. Actor-network analysis to the service system of youth market.

\section{Conceptual framework for assessing social capital accumulation}

The purpose of this research is to assess how social capital accumulates along with the service system development. Our field works indicated the development of service system was comprised with a series of decision making for responding to specific structural holes [51], which revealed the disconnection of networks in the system. As the aforementioned theoretical background, a service system could be described as an integration of operand and operant resources. Those key actions could be seen as transections of operant resource with knowledge and technique based on the self-interest of actors. For example, the common goal of revitalizing DMM by creating DMYH was finally reached through the engagement of CBGP, such as youth startups creating close relationship between other actors for stabilizing their business, several original store owners increasing their business hours to the evening for catching new consumers. With the S-DL view [7], each action accompanied with certain value proposed or received in the service system could be seen as the investment of operant resources presented in the form of structural, relational, and cognitive capital according to their attributes. System development is a process that actors pursue self-interest through the OPP [21]. To overcome their obstacles, the invested social capital would contribute to the entire service system.

\subsection{The generation of assessment matrix for social capital accumulation}

Considering the service system development as a continuous progress, unique patterns were found from our fieldworks. It could be described as a learning process, for maximizing the self-interest along with the long-term system development. Basically, the visible changes in the field moved slightly and slowly, which may be affected by the organizational learning in routines that were conceptualized as a cycle of plans, actions, outcomes and ideals. As the result, the process indicated a routine can be change and still be the same routine [52]. Data identified from the service system analysis showed the similar patterns strongly fit the theoretical framework.

In the service system of declined market, interview reports indicated a low confidence that key actors felt from the DMM. The common impression was "dirty, dark, and scary because of the closed rolling steel doors." Original store owners acted xenophobic to "outsiders" because they felt "being taken advantage of to finish unrelated businesses" from the past-failed revitalizations. In the long-term plan, even than the requirements of the administrators, the city government, were still unclear, such as "we (government) are going to revitalize this market by creating new businesses", "the CBGP will help us plan the process, and we just have to coordinate." As the action, the KMS was founded to perform the role of focal actor, carrying the mission of connecting the field to the CBGP. The outcomes were holding events with young generation to create the value so called "the youth are back" to the DMM. Store owners "haven't seen so many visitors like that for a long time," and said "I (owner) was used to think my place was not worth visiting, but now I think they (visitors) are interested." Their mind changed finally leading to the system development; for example, some of them increased business hours till evening, becoming a part of youth market. These changes were the opening of the revitalization, which involved a plenty of 
relationship and cognition changes in the entire process. The key resource identified from the field were the knowledge that enabled the facilitators to plan the progress and the technique that connected the value of old market to the stakeholders' foci.

The revitalization was a series of tiny changes such as the aforementioned examples, driven by operant resources that accumulated social capitals to the system. By the identified field insight and the reviewed literature, we proposes a sequential framework of social capital accumulation. The beginning of the sequence is a tangible system with structural capital, then derivatize relationship based on the created interactions. The derivatized relationship would also generate corresponding capital to the system, then trigger the qualitative conversion during value co-creation on the level of cognition. By the generated common view, the tacit cognitive capital will be transformed to the form of explicit relationship and finally be systematized. We use this framework to develop a matrix for assessing the accumulation of social capital, which is demonstrated by assessing DMM service system development (

Table 2).

Table 2. Assessment matrix for the social capital accumulation

\begin{tabular}{|c|c|c|c|c|c|c|}
\hline \multicolumn{7}{|c|}{ Description of Social Capital Accumulation } \\
\hline & Structural Capital (S1) & Relational Capital (R1) & Cognitive Capital (C1) & Relational Capital (R2) & Structural Capital (S2) & \\
\hline 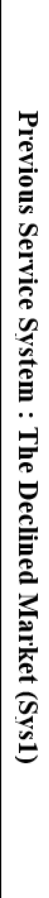 & $\begin{array}{l}\text { 1. Morning market service } \\
\text { provision (SO). } \\
\text { 2. Regular CBGP meetings } \\
\text { were hold between LU, } \\
\text { KMS, and Gov. } \\
\text { 3. Events and learning } \\
\text { activities held (KMS, LU). }\end{array}$ & $\begin{array}{l}\text { 1. Personal relationship } \\
\text { created during the } \\
\text { morning market (SO, } \\
\text { KMS). } \\
\text { 2. Prior personal meetings } \\
\text { were hold before formal } \\
\text { ones for exchanging } \\
\text { information and make } \\
\text { consensus because of the } \\
\text { trust (LU, KMS, Gov). } \\
\text { 3. Event participants created } \\
\text { personal relationship to } \\
\text { the market actors (KMS, } \\
\text { LU, SO). } \\
\text { 4. YS were interested in } \\
\text { DMM, then contacting the } \\
\text { KMS for more } \\
\text { information. }\end{array}$ & $\begin{array}{l}\text { 1. Suspicion had changed to } \\
\text { expectation in the daily } \\
\text { interaction (SO, KMS). } \\
\text { 2. The common goal of } \\
\text { creating DMYH was } \\
\text { reached since the long-tern } \\
\text { collaboration (LU, KMS, } \\
\text { Gov). } \\
\text { 3. Proportional event } \\
\text { participants changed their } \\
\text { negative cognition of } \\
\text { DMM, then becoming NC. } \\
\text { 4. More YS believed that } \\
\text { their business could really } \\
\text { stabilize in DMM. } \\
\text { 5. More citizens were willing } \\
\text { to understand DMM, then } \\
\text { becoming NC. }\end{array}$ & $\begin{array}{l}\text { 1. Several SO started to open } \\
\text { their mind to the NC, and } \\
\text { created new relationship } \\
\text { 2. The collaboration of CBGP } \\
\text { turned to a truthful } \\
\text { relationship between actors } \\
\text { (LU, KMS, Gov). } \\
\text { 3. The NC started to } \\
\text { connected their personal } \\
\text { networks to DMM. } \\
\text { 4. YS created close relation- } \\
\text { ship between other actors } \\
\text { for stabilizing business. } \\
\text { 5. NC started to search for } \\
\text { effective ways to } \\
\text { understand DMM by } \\
\text { creating relationship to } \\
\text { other actors. } \\
\text { 6. An intangible relationship } \\
\text { was created during the } \\
\text { actors were referred to each } \\
\text { other. }\end{array}$ & $\begin{array}{l}\text { 1. Several SO increased their } \\
\text { business hours to the } \\
\text { evening for catching the } \\
\text { new consumers. } \\
\text { 2. The DMYH was created as } \\
\text { the indicative outcome of } \\
\text { CBGP, which attracted } \\
\text { more people to engage } \\
\text { (LU, KMS, Gov). } \\
\text { 3. The connected consumer } \\
\text { networks had created } \\
\text { many "market fans,", } \\
\text { sharing the development } \\
\text { of DMM continuously } \\
\text { (NC). } \\
\text { 4. A collaborative view of } \\
\text { resources-sharing was } \\
\text { created as the YS stabilizes } \\
\text { their business. } \\
\text { 5. Some NC asked the KMS } \\
\text { for the guided tour service. } \\
\text { 6. The KMS became the } \\
\text { integrator in the intangible } \\
\text { relationship, acting as the } \\
\text { information hub of DMM. } \\
\text { 7. Online communication } \\
\text { channels were created } \\
\text { between actors, which } \\
\text { enabled them to report } \\
\text { loopholes of DMM (LU, } \\
\text { KMS, Gov, YS). } \\
\text { S1+R1+C1+R2+S2 }\end{array}$ & 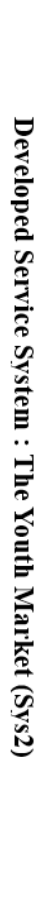 \\
\hline
\end{tabular}

*Actors: Local Universities (LU), City Government (Gov), KhuiMng Studio (KMS), Original Store Owners (SO), Youth Startups (YS), New Consumers (NC)

\subsection{The processes of assessing social capital accumulation}

With the assessment matrix (Table 2), the social capital accumulation process can be identified and described following the sequence of "structural relational - cognitive - relational - structural" capital from the service system of declined market (Sys1) to the service system of the youth market (Sys2). The five columns on the top row mark the analysis target of each procedure. The five columns of the central matrix are the main content that describe the patterns collected from service systems. Serial number is used to mark the patterns with causality. The code showed in bottom row act as reminders that facilitate readers to clarify the analyzed capital since the field data usually mix with information about all dimensions of social capital from the beginning of data collection period.

The development of specific services in the system can be tracked by the assessment matrix. For example, the content number 1 in the matrix tracks down the social capital accumulation about the developed services that original store owners do the business in the evening. The structural capital analysis in the left column (S1) shows that Sys1 only provides market service. Then, the relational capital analysis 
column (R1) shows the personal relationship was created between the store owners and the KMS. In this step, the remained items in the bottom of that column indicate that the analyzed capital is the accumulation of previous structural capital and the add-on relational capital $(\mathrm{S} 1+\mathrm{R} 1)$. That is, we can find that the personal relationship (R1) is accumulated on the tangible service provision channel (S1). Then, the change of store owners' mind from suspicion to expectation is identified in the cognitive capital analysis $(\mathrm{C} 1)$, which indicates that the cognition change is the accumulation outcome from the previous capital $(\mathrm{S} 1+\mathrm{R} 1+\mathrm{C} 1)$. We can find that several store owners decided to open their mind and creating new relationships with the new consumers in the next relational capital analysis column (R2), which finally drive them to increase their business hours to the evening for catching new customers as the structural capital of the service system (S2). Again, the remained items in the bottom row indicate the attributes of accumulation, explaining the service provision by the original store owners in the evening is the outcome of a sequence of social capital accumulation $(\mathrm{S} 1+\mathrm{R} 1+\mathrm{C} 1+\mathrm{R} 2+\mathrm{S} 2)$.

Tracing back to the actor-network analysis in the case study part (Figure 2 and 3 ), the motivations of the original store owners in these two identified service systems are the same, to earn money. Actions they took are in the purpose of overcoming the obstacles, such as the lack of consumers and the disability on attracting new customers. Social capital was created along with their actions, and then accumulated on the system level. With the S-DL view, it's a process, including both value co-creation and co-destruction, affected by involved stakeholders with different levels of power in the service systems. In this case, only few original store owners changed their habits for catching new customers. No matter the interpretation is on the direction of adaptation or compromise, the co-created value had already become a part of the identified service system. Along with the completion of the matrix, the process of social capital accumulation reveals strong evidences to denote the progress of service system development, and the structural holes within.

\section{Discussions and conclusion}

This research proposes a conceptual framework to study the development of a service system. With the assessment matrix, the main research question that how social capital is accumulated along with the development of a service system is answered by the long-term case study on the service system of DMM revitalization.
First, for the discussion of how social capital is accumulated along with service system development, three dimensions of social capital were used in the study for checking the interaction between stakeholders. The S-DL view is adopted to explain the value creation within the service system by the form of actor-network analysis. The development of service system can be seen as the integrated value including both co-creation and co-destruction, which generate and exchange the social capital to the system. With the value-oriented perspective, the intangible attributes of social capital, especially the relational and cognitive dimensions, can be gathered for discussing in the same level, providing insight to analyze the system development in a more comprehensive way.

Second, due to the important connection between social capital accumulation and service system development, a framework is proposed to study its processes rather than the performance which has been focused in prior researches. With the assessment matrix that integrates the social capital through the system development dimension, the insights of how the service system of a declined market was transformed to a youth market were revealed. For example, according to the matrix, the attribute that the original stores opened in the evening could be traced back from the personal relationship creation to the mind-opening along with a long-term interaction; the creation of the DMYH could be traced back to the consensus made in a series of integration. They all involved specific knowledge and technique that allowed the key actors to create new connections for cognition change; thus, emphasizing the importance of operant resources in accumulating social capital. This framework takes advantage of our previous works about a method of service system analysis by the integration of S-DL and ANT [22], and the value creation analysis method using social capital theories [14], and then extends to the longitudinal scale for studying the long-term development of service systems. The field insights and literature provide the clues that enable us to develop a sequence of actions to assess the accumulation process, which follows the order of "structural - relational - cognitive - relational - structural" capital.

Finally, the most important issue is the extension of our findings. In this research, the field data from DMM service system revitalization are used to verify the proposed framework. The major actors of the service systems were identified with their obstacles and goals according to the actor-network analysis, and the insights about their actions were sorted to conclude the assessment matrix. By the sequential procedure, the development of every component of the service system are analyzed. We can easily check the matrix 
for trace back the generation and exchange of social capital. Of course, the direction between service system development and the social capital accumulation process are not always synchronize. A system development with expending services (increase from 3 contents to 7 contents in

Table 2) was found according to the developing case of DMM revitalization in this research. However, the social capital accumulation may also lead to the system shrinkage if the development is on the negative direction. For example, several issues addressed in Section 3.3 reveal the complex problems of resources distribution and governmental administration which may harm service systems. Although there are still not enough evidences, we think it will probably decrease the system development because the conflict may happen in the social capital accumulation process on the relational dimension in the future.

Although the findings of this research are encouraging with great potential, several limitations are identified in this study. The major challenge is the generalizability. Similar to other works done by case study, the field of DMM revitalization is a unique scenario that contains specific ethical and political issues. Some data was collected based on the created long-term truthful relationships. It may be the obstacle while generalizing the framework to other cases since most of the valuable field data are sensitive and interest-involved. Intangible capital on relational and cognitive dimensions could be correctly defined without the truth between subjects and the researchers. The other challenge is about the common understanding of the S-DL. In general, research subjects in the field have no idea about the valueoriented perspective, let alone the value creation process. It takes time for the researchers to clarify the objective contents from the subjective feedbacks. Those two identified challenges become the limitation that decrease the performance of our assessment if the data quality is not enough to describe the development of the service system. It indicates that only long enough collection period crossing the transformation of service systems could provide data to substantiate this framework, which increases the difficulty on generalization.

In summary, since this is one of very few papers to using S-DL view for assessing social capital accumulation process rather than its performance, it shed light on explicating the social capital accumulation process for service system development. Applying the value-oriented view provides not only the way to study the intangible dimensions of social capital, but also potential ways of data collection for scholars and social workers to analyze the service system development by social capital. We anticipate the framework of assessing the social capital accumulation can reveal the structural holes of service systems by analyzing the accumulated conditions, facilitating the decision making of various actors, and communicating value propositions with the general public.

\section{References}

[1] G. Lay, (Ed.), "Servitization in industry," Springer, 2014.

[2] C. Lerch, "Servitization as an Innovation Process: Identifying the Needs for Change," in Servitization in Industry, Springer, Cham, 2014, pp. 179-189.

[3] K. Mori, T. Fujii, T. Yamashita, T. Mimura, Y. Uchiyama, and K. Hayashi, "Visualization of a City Sustainability Index (CSI): Towards transdisciplinary approaches involving multiple stakeholders," Sustainability-Basel. 7(9), pp. 12402-12424, 2015.

[4] K. P. Bithas, and M. Christofakis, "Environmentally sustainable cities. Critical review and operational conditions," Sustainable Development, 14(3), pp. 177-189, 2016.

[5] M. Alberti, "Measuring urban sustainability." Environmental impact assessment review, 16, pp. 381-424, 1996.

[6] S. L. Vargo, and R. F. Lusch, "Institutions and axioms: an extension and update of service-dominant logic," Journal of the Academy of Marketing Science, 44(1), pp. 5-23, 2016.

[7] R. F. Lusch, and S. L. Vargo, "Service-dominant logic: Premises, perspectives, possibilities," Cambridge University Press, 2014.

[8] S. P. Singaraju, Q. A. Nguyen, O. Niininen, and G. SullivanMort, "Social media and value co-creation in multistakeholder systems: A resource integration approach," Industrial Marketing Management, 54, pp. 44$55,2016$.

[9] C. Tynan, S. McKechnie, and C. Chhuon, "Co-creating value for luxury brands," Journal of Business Research, 63(11), pp. 1156-1163, 2010.

[10] L. Plé, and R. Chumpitaz Cáceres, "Not always co-creation: introducing interactional co-destruction of value in servicedominant logic," Journal of Services Marketing, 24(6), pp. 430-437, 2010.

[11] I. N. Chowdhury, T. Gruber, and J. Zolkiewski, "Every cloud has a silver lining - Exploring the dark side of value co-creation in B2B service networks," Industrial Marketing Management, 55, pp. 97-109, 2016.

[12] W. Tsai, and S. Ghoshal, "Social capital and value creation: The role of intrafirm networks," Academy of Management Journal, 41(4), pp. 464-476, 1998.

[13] M. Granovetter, "Economic institutions as social constructions: a framework for analysis," Acta sociologica, 35(1), pp. 3-11. 1992.

[14] N.A. Windasari, F.R. Lin, and H.W. Chen, "The Role of Social Capital on Cocreating Value for Social Enterprises: The Service Dominant Logic Perspective, " Paper presented at the Hawaii International Conference on System Science 2017 (HICSS-50), Jan 4-7, 2017, uri/doi: http://hdl.handle.net/10125/41352

[15] G. T. Blessi, D. G. Tremblay, M. Sandri, and T. Pilati, "New trajectories in urban regeneration processes: Cultural capital as source of human and social capital accumulationEvidence from the case of Tohu in Montreal," Cities, 29(6), pp. 397-407, 2012.

[16] K. Teilmann, "Measuring social capital accumulation in rural development," Journal of Rural Studies, 28(4), pp. 458-465, 2012. 
[17] D. R. Krause, R. B. Handfield, and B. B. Tyler, "The relationships between supplier development, commitment, social capital accumulation and performance improvement," Journal of operations management, 25(2), pp. $528-545,2007$.

[18] S. Kumra, and S. Vinnicombe, "Impressing for success: A gendered analysis of a key social capital accumulation strategy," Gender, Work \& Organization, 17(5), pp. 521546, 2010.

[19] A. Antoci, P. L. Sacco, and P. Vanin, "Social capital accumulation and the evolution of social participation," The Journal of Socio-Economics, 36(1), pp. 128-143, 2007.

[20] S. Y. Lee, "The effects of green supply chain management on the supplier's performance through social capital accumulation," Supply Chain Management: An International Journal, 20(1), pp. 42-55, 2015.

[21] M. Callon, "Some elements of a sociology of translation: domestication of the scallops and the fishermen of St Brieuc Bay," The Sociological Review, 32(1_suppl), pp. 196-233, 1986.

[22] F. R. Lin, and S. Y. Wang, "Service Value Network Formation for Organic Agricultural Produce: An Actor Network Theory Perspective," In System Sciences (HICSS), 2014 47th Hawaii International Conference on (pp. 12961305). IEEE.

[23] R. Andrews, "Exploring the Impact of Community and Organizational Social Capital on Government," Political Research Quarterly, 64(4), pp. 938-949, 2011.

[24] N. Mukherjee, "Measuring Social Capital: Forest Protection Committees in West Bengal, "Economic and Political Weekly, 37(29), pp. 2994-2997, 2002.

[25] Y.Q. Sun, Y.L. Fang, K.H. Lim, and D. Straub, "User Satisfaction with Information Technology Service Delivery: A Social Capital Perspective, " Information Systems Research, 23(4), pp. 1195-1211, 2012

[26] M. M. Wasko and S. Faraj, "Why Should I Share? Examining Social Capital and Knowledge Contribution in Electronic Networks of Practice, " MIS Quarterly, 29(1), pp. 35-57, 2015.

[27] J. Wang, J.Y. Lai, and L.C. Hsiao, "Value network analysis for complex service systems: a case study on Taiwan's mobile application services, " Service Business, 9(3), pp. 381-407, 2015

[28] P. Bourdieu, "The forms of capital," in Handbook of theory and research for the sociology of education, J. G. Richardson, Ed., ed: New York: Greenwood, pp. 241-258, 1986.

[29] F. Fukuyama, Trust: The social virtues and the creation of prosperity, New York: The Free Press, 1995.

[30] N. Lin, "Building a network theory of social capital," Connections, 22, pp. 28-51, 1999.

[31] R. D. Putnam, "The prosperous community," The American prospect, 4, pp. 35-42, 1993.

[32] P. S. Adler and K. Seok-Woo, "Social capital: Prospects for a new concept," The Academy of Management Review, 27, pp. 17-40, 2002.

[33] J. Nahapiet and S. Ghoshal, "Social Capital, Intellectual Capital, and the Organizational Advantage, " The Academy of Management Review, 23(2), pp. 242-266, 1998.

[34] A. R. Anderson and S. L. Jack, "The articulation of social capital in entrepreneurial networks: a glue or a lubricant," Entrepreneurship \& Regional Development, 14, pp. 193-210, 2002.

[35] J. Liao and H. Welsch, "Roles of social capital in venture creation: Key dimensions and research Implications," Journal of Small Business Management, 43, pp. 345-362, 2005.

[36] A. Rajennd, L. Muniady, A. Al Mamun, P. Y. Permarupan, N. R. B. Zainol, and M. R. Mohamad, "Social capital: Cross- industry and cross-state comparison among Malaysian women micro-entrepreneurs," Mediterranean Journal of Social Sciences, 7, pp. 350, 2016.

[37] M. C. Bolino, W. H. Turnley, and M. B. James, "Citizenship behavior and the creation of social capital in organizations," The Academy of Management Review, 27, pp. 505-522, 2002.

[38] A. C. Inkpen and E. W. K. Tsang, "Social capital, networks, and knowledge transfer," The Academy of Management Review, 30, pp. 146-165, 2005.

[39] M. Granovetter, Problems of Explanation in Economic Sociology. Boston: Harvard Business School Press, 1992.

[40] P. P. Maglio, S. L. Vargo, N. Caswell, and J. Spohrer, "The service system is the basic abstraction of service science," Information Systems and e-Business Management, 7(4), pp. 395-406, 2009.

[41] M. Warg, P. Weiß, R. Engel, and A. Zolnowski, "Service Dominant Architecture based on SD logic for Mastering Digital Transformation: The Case of an Insurance Company," Tiziana Russo-Spenaand Cristina Mele, pp. 807, 2016.

[42] P. Ekman, R. D. Raggio, and S. M. Thompson, "Service network value co-creation: Defining the roles of the generic actor," Industrial Marketing Management, 56, pp. 51-62, 2016.

[43] B. Latour, Reassembling the social: An introduction to actor-network-theory. Oxford university press. 2005.

[44] J. Walton, "The obligatory passage point: abstracting the meaning in tacit knowledge," Proceedings of European Conference on Knowledge Management. Academic Conferences International Limited; September, 2013; pp. 769.

[45] G. L. Simon, "If you can't stand the heat, get into the kitchen: obligatory passage points and mutually supported impediments at the climate-development interface," Area. 46(3), pp. 268-277, 2014

[46] K. O'reilly, Ethnographic methods. Oxon: Routledge. 2012.

[47] C. Geertz, "Thick description: Toward an interpretive theory of culture," In Readings in the philosophy of social science, 1st ed.; Martin, M., McIntyre, L. C., Eds.; Mit Press, pp. 213-231, 1994; ISBN: 9780262631518.

[48] M. Angrosino, Doing ethnographic and observational research. Sage, 2007; ISBN: 9780761949756.

[49] S. González, and P. Waley, "Traditional retail markets: the new gentrification frontier?," Antipode, 45(4), pp. 965-983, 2013.

[50] J. I. Kim, C. M. Lee, and K. H. Ahn, "Dongdaemun, a traditional market place wearing a modern suit: the importance of the social fabric in physical redevelopments," Habitat International, 28(1), pp. 143-161, 2004.

[51] R. Burt, "Structural holes and good ideas," American journal of sociology, 110(2), pp. 349-399, 2004.

[52] M. S. Feldman, "Organizational routines as a source of continuous change," Organization science, 11(6), pp. 611629,2000 